\title{
Prevalence of Hospital Acquired Infection and Associated Factors Among Patients Admitted, at Hawassa University Comprehensive Specialized Hospital Getachew Melakie 1, Embialle Mengistie2, Tesfaye Ashenafi3, Busera Seman4 1' 2'3 Hawassa University Dep
}

Getachew Melakie ( $\sim$ getishmelak@gmail.com )

Hawassa University

Embialle Mengistie

Hawassa University

Tesfaye Ashenafi

Hawassa University

Busera Seman

hawassa health science college

Research Article

Keywords: hospital acquired infection, prevalence and risk factors

Posted Date: March 7th, 2022

DOI: https://doi.org/10.21203/rs.3.rs-1399139/v1

License: (c) (i) This work is licensed under a Creative Commons Attribution 4.0 International License.

Read Full License 


\section{PREVALENCE OF HOSPITAL ACQUIRED INFECTION AND ASSOCIATED FACTORS AMONG PATIENTS ADMITTED, AT HAWASSA UNIVERSITY COMPREHENSIVE SPECIALIZED HOSPITAL}

Getachew Melakie ${ }^{1}$, Embialle Mengistie ${ }^{2,}$ Tesfaye Ashenafi ${ }^{3}$, Busera Seman ${ }^{4}$, Amanuel Ejesso $^{5}$

${ }^{\prime} 2^{\prime} 3^{\prime} 5$ Hawassa university department of Environmental health, in hawassa, sidama regional state, Ethiopia;

${ }^{4}$ Hawassa College of health science midwifery department, in hawassa, sidama regional state, Ethiopia

Correspondence: Getachew Melakie Akele

$\underline{\text { Tel: }+251932646213}$

Email: getishmelak @gmail.com 


\section{Abstract:}

Purpose: Hospital acquired infection (HAI) is an infection acquired a major global concern of wellbeing, affecting the quality of care in the health care setting. Routine surveillance of infection is an important part of infection prevention (IP) and quality assurance in hospitals. The objective of this study was to determine the prevalence and associated factors of HAI at inpatients, in Hawassa university comprehensive specialized hospital (HUCSH).

Method and materials: A weekly based cross-sectional study was conducted at inpatients in HUCSH. All eligible inpatients admitted for at least three days on the day of survey were included. The study was conducted from June 28/2021 to August 23/2021. Environmental health professionals and nurses collected the data according to the Centers for Disease Control through observational assessment documented by physician. Coded and cleaned data from Epi-data version 3.5 were transferred to SPSS version 23 for analysis. Univariate and multivariable logistic regression analyses were used to determine the prevalence of HAIs and associations between independent and dependent variables. .

Results: A total of 413 patients were included in this survey, the median age of the participants was 26 years (interquartile range:3 month to 80 years). A total of 352 (85.2\%) patients diagnosed with non-fatal disease during the survey. There were 49 patients with HAI, with a mean prevalence of $11.9 \%$. Coagulate negative staphylococcus (CONS) 27.27\%), and E. coli (27.27) were the most frequently reported HAI-causing pathogens from the result of culture. The association of patients admission diagnosis (admit with rapidly fatal disease and ultimately fatal disease), length of hospital stay (more than five days of hospital stay) and absence of running tap water at patients room with the occurrence of HAI were statistically significant.

Conclusion: Surgical site infections (SSI) and blood stream infection (BSI) were the most common types of HAIs. The proportion of HAIs among wards, indicated a large variability. Therefore, Hospital management and health care workers (HCWs) should give more attention on the practice of infection prevention (IP) in order to achieve a reduced prevalence of HAIs in the study setting.

Keywords: hospital acquired infection, prevalence and risk factors 


\section{Background}

Epidemiologically, infections that are related to surgical or other medical and/or procedural interventions and those that are caused by multidrug-resistant organisms are linked to healthcare settings [1].

Hospital-acquired infection (HAI) is defined as a localized or systemic condition that results from adverse reactions to the presence of an infectious agent(s) or its toxin(s), and that patients get while receiving treatment for medical or surgical conditions and was not incubating at the time of admission [2].

HAIs occur in all settings of care and the most common clinical focus of infection ranged from relatively mild cases of localized or upper respiratory infections to more systemic or disseminated infections of life-threatening bloodstream infections [3]. Of the multitude of HAIs that can occur in a clinical setting, many of the highest proportions are associated with bacterial pathogens [4].

All hospitalized patients are susceptible for HAIs, however long hospital stays, invasive medical device exposure and surgical complications [5] and overuse of antibiotics are more likely to get an infection [6].

HAI can lead to prolonged hospital stays, mortality and additional costs to patients and health care delivery system; For example, In American hospitals alone, the Centers for Disease Control (CDC) estimates that HAIs account for an estimated 1.7 million infections and 99,000 associated deaths each year, where patients with HAI, who spend, an additional 6.5 days in the hospital, are twice as likely to die, surgical infections are believed to account for up to ten billion dollars annually in healthcare expenditures [3].

The prevalence of HAI revealed high a teaching hospitals in Africa such as the prevalence in Uganda 28\%, Ghana14\% [7], and Ethiopia 7.4\% to19.4\% [8-10] were higher than the prevalence reported from USA (8.7\%) [11] and china (4.26\%) [12]. On top of that, extended-spectrum betalactamase producing Gram-negative bacilli (1.9\% to 53.0\%) were the most reported antimicrobial resistant pathogens for causing HAIs [13]. Hence, these pathogens displayed considerable resistance to treatment and are considered priority pathogens for research and development of new antibiotics [14].

There have been advances in healthcare systems and technology pertaining to prevention of HAI among the public and policymakers [4]. For instance the CDC/NHSN planned a national target for improvement since 2013, with a goal of total elimination by 2020 ; as a result, it showed a $16 \%$ 
reduction in United States of America since 2011 to 2015 and revealed to 3.2\% for overall prevalence [4]. Despite this fact, it remains a great threat to the quality of healthcare delivery systems particularly in Africa, which is due to infection control and HAI prevalence reports are relatively not well recognized due to lack of centralized guidelines and resources from most hospitals in Africa [15].

Studies also identified the contributing factors for HAI and revealed that, patients' underlying medical condition[16-18], history of previous hospitalization[10, 16], and severity of Illness [19] and demographic characteristics such as age less than 14 years [10], male gender [10] and type of ward such as ICU [16] were found to be important factors associated with increased risk of HAI. However, the burdens of HAI can be giant with regard to complex routes of transmission [6], dynamic nature of HAI with respect to infection-control procedures in the healthcare environment [20]. On top of that most published studies on HAI conducted from the study setting were limited with specific ward [21] and patient age [22].

Hence, routine surveillance of HAIs at inpatient ward is an integral part of infection prevention and quality assurance in hospitals [23]. Therefore, conducting a comprehensive research was important to determine the magnitude and associated factors of HAI in HUCSH. 


\section{Material and methods \\ Study Setting and population}

A cross-sectional study was conducted to determine the prevalence of HAI in HUCSH. A total of 400 inpatient beds are available in the hospital, which serve as a comprehensive specialized referral and teaching hospital in the Sidama region and surrounding zones and regions. However due to renovation of the building only 233 beds were allowed for inpatient services in the selected hospital. All inpatients admitted to the hospital were included in the study. Wards of all specialties, including surgical, obstetrics and gynecology, internal medicine, pediatrics, ophthalmology, and intensive care unit (ICU), were included, whereas the wards associated with neonatal intensive care and oncology units, emergency and recovery departments were excluded from the study.

\section{Sample size and Sampling technique}

The sample size was calculated by using a single population proportion formula. And after considering $10 \%$ contingency, 422 sample size was required.

$$
\begin{aligned}
& n=\left(z_{2}^{\alpha}\right)^{2 *} \quad \frac{p(1-p)}{d^{2}}, n=(1.96)^{2} \times \frac{0.5(0.5)}{(0.05)^{2}}=\frac{3.8416 * 0.25}{0.0025}=\frac{0.9604}{0.0025}=384.16=384 \\
& +10 \%=422
\end{aligned}
$$

Where; $\mathrm{n}=$ sample size

$\mathrm{Z} \alpha / 2=$ critical value for standard normal distribution (Z-statistic) at $95 \%$ confidence level $(\mathrm{z}=1.96)$.

The sample size was proportionally allocated to type of inpatient departments, according to the respective size of beds distribution; pediatric department ( 69 beds), surgery departments ( 76 beds), internal medicine department ( 32 beds), gynecology ward ( 32 beds), and mixed wards ( 24 beds), which includes intensive care units (11beds) and ophthalmology department (13beds). Data were collected by five trained nurses (clinical and demographic data from medical charts) and three trained Environmental health professionals (reviewed infection prevention data documented from the wards weakly infection prevention follow-up checklists), which is assessed on every morning session or at 4:00 AM local time in Monday. Data were collected for two months, which is from June 28/2021 to August 23/2021 though a weekly based continuous way. Finally, the first study participant was selected randomly from the first room independently in each inpatientward.whereas all other allocated eligible participants were selected by using systematic random sampling or using every two other eligible patients bed interval and independently in each 
ward. Hence, the total number of in-patients expected per month (once per week) were 652.4, which was determined by taking $70 \%$ bed occupancy rate of the hospital. It was a regular weekly based procedure, until the achievement of allocated sample size in each department. When incomplete data were resulted from the eligible participant, it was replaced by the preceding eligible participant in the same ward.

As a result, the prevalence of HAI was determined based on the United States CDC checklist used to confirm HAI. Data's were collected after the ethical approval of hawassa university College of Medicine and Health Science Institutional Review Board.

Figure1 Proportional allocation of sample size to type of inpatient wards in HUCSH, based on size of inpatient beds.

\section{Data collection tools}

Data were collected by using a pretested observational tool having two part (clinical and environmental part). The tool were adapted from the previous study [8], and modified based on CDC standard [2]. Two day training was given for all data collectors (eight) and supervisor (one). Medical records and consultation with the person in charge of the patient were used for the identification of the infection. Data were collected based on the signs and symptoms and the specific site criteria, as recommended by CDC. 


\section{Data quality and management}

After getting permission letters, two day training were given for data collectors regarding the definitions and the study protocol prior to starting the study. The tools were pretested among 12 patients selected from three wards (gynecology, pediatric and orthopedic wards); then the actual data were collected and comparison was made.

Intensive supervision was held for its completeness and corrective discussion among all the research team members was conducted at the end of each day. All independently collected data were immediately matched by date, room number and ward. As a result, the missed and incomplete

response in the questionnaire was corrected accordingly. The completed collected data were entered into Epi data version 3.5 after immediate checkup.

At the end of study period, the completed entered data was transported into SPSS version 23 for analysis.

\section{Data Entry and Analysis}

Data were entered and coded by using Epi data version 3.5. Then the complete entered data was exported into SPSS version 23 for analysis.

Descriptive statistics was used to calculate the prevalence of HAI. The prevalence of HAI was determined by conducting proportion, which is calculate by number of infections divided by the total number of patients comprising the study population.

Binary logistic regressions were conducted between the dichotomies dependent (HAI) and independent variables.

Finally, independent variables that have a bivariate relationship of significance, $\mathrm{P}<0.20$ in chisquare tests were entered into multivariate binary logistic analysis.

In multivariable binary logistic regression analyses variables with Odds ratio, estimated with 95\% confidence interval and $\mathrm{P}<0.05$ was considered the independent predictor of HAI.

Model fitness was also checked by using Omnibus Tests of Model Coefficients, in which -2LL is Significantly different with the base model Hosmer-Lemeshow's Goodness of Fit test greater than 0.05 was considered as good model fit to final prediction. Cox \& Snell and the Nagelkerke R Square (pseudo R square statistics) was also observed to model prediction (0 to 1 scale), in which the higher value indicated that the model predicts well. 


\section{Operational Definitions}

Hospital acquired infection (HAI): were confirmed if the patient had signs and symptoms and/or laboratory data, which met the Centers for Disease Control and Prevention (CDC); hence, HAI were defined as a localized or systemic condition that required to meet the diagnosis of site-specific infection and occurring for the first time on or after the $3^{\text {rd }}$ calendar day of admission to an inpatient location where a day after admission is counted as calendar day one [2].

McCabe score: used to classify severity of medical conditions [24]

Nonfatal disease: expected survival, $\geq 5$ years, includes; diabetes mellitus (DM), inflammatory disease and obstetrics cases

Ultimately fatal: expected survival 1-5 years; chronic leukemia, lymphomas, metastatic carcinoma, end-stage kidney disease, multiple sclerosis,

Rapidly fatal: expected survival $<1$ years; heart failure, multiple organ failure, pulmonary disease with cor pulmonale

Previous hospital admission: patients who had a history of hospital admission within a month.

Antibiotic use: all oral, rectal, intramuscular (IM) and intravenous (IV) treatment for the diagnosis other than HAI and it may be prescribed for prophylaxis or therapeutic purpose [2].

Length of hospital stay (LOS): were duration of inpatient care (in days), which was counted from the patient's admission date to date of first laboratory test or examination or procedure if patient had HAI or date of admission up through date of survey if patient had no HAI; where a day after admission date is counted as calendar day one [2].

Sufficient ventilation system: were defined if the ratios of total openable area of window $\left(\mathrm{m}^{2)}\right.$, opposite to door to floor area $\left(\mathrm{m}^{2}\right) \geq 10 \%$, with or without mechanical or other artificial ventilation system in the patient's room [25] 


\section{Results}

A total of 422 hospitalized patients were expected to be enrolled in this study. However, the clinical information obtained from 9 participants' medical records were incomplete, and were excluded from the analysis. Hence, the complete data obtained from the 413 patients $(97.86 \%)$ were included for final analysis.

There were no active surveillance programs on HAIs in any of the participating wards. Participants enrolled from surgical (32.69\%) and pediatric (30.27\%) wards constituted the highest proportion and the least proportion $(8.96 \%$ ) were included from mixed wards (ICU and ophthalmology wards).

The mean age of participant in years was 27. The median age of the participants was 26 years (varied from 3 month to 80 years) and the higher proportion (36.8\%) of them were aged between 15-34 years. Of the total respondents, more than half $(55.2 \%)$ of the participants were female. According to the criteria for severity of underlying medical condition (McCabe scores) or admission diagnosis, the majority $(85.2 \%)$ of the study participants were diagnosed with non-fatal disease. The mean length of hospital stay (treatment), in days was 6.37.

The median length of stay of the total participant was 5 days. $54.2 \%$ of the participants stayed below or equals to five days (median length of treatment).

Almost half $51.6 \%$ of the study participants underwent surgical procedures. $80.15 \%$ of the participants received antibiotic therapy (either prophylaxis or therapeutic) for their diagnosis after admission (95\%CI: 76.5-84.0).

The overall prevalence of HAI was $11.9 \%(n=49)(95 \%$ CI: 8.7-15.7). None of the participants were identified with more than one episode of HAIs. SSI (38.8\%) and BSI (34.7\%) were the most frequently reported clinical focus of HAIs. Microorganisms were also reported among $44.9 \%$ of the participants with HAI and the pattern of pathogens by specific clinical focus of infection varied from $9.1 \%$ in UTI to $77.3 \%$ in BSI. Of the reported causative bacterial species, $22.73 \%$ of pathogens were not differentiated by specific genus level and identified through gram stain. In addition, coagulate negative staphylococcus (CONS) 27.27\%), and E. coli (27.27) were the most frequently isolated pathogens from HAIs.

The prevalence of HAIs differed across inpatient wards, which is 0 in ophthalmology ward to $26.5 \%$ in orthopedic wards. As a result the overall prevalence among type of wards ranges from $2 \%$ in mixed age wards to $36.7 \%$ in pediatric wards. 
Table 1 Demographic and clinical characteristics of patients who participated in the survey $(n=413)$

\begin{tabular}{|c|c|c|}
\hline Variable & Characteristics & Number of patients (\%) \\
\hline \multirow[b]{2}{*}{ Sex } & Male & $185(44.8)$ \\
\hline & Female & $228(55.2)$ \\
\hline \multirow{5}{*}{ Age (years) } & $<1$ & $15(3.6)$ \\
\hline & $1-14$ & $114(27.6)$ \\
\hline & $15-34$ & $154(37.3)$ \\
\hline & $35-55$ & $88(21.3)$ \\
\hline & $\geq 56$ & $42(10.2)$ \\
\hline \multirow[t]{5}{*}{ Ward type } & Internal medicine & $58(14)$ \\
\hline & Surgery ward & $135(32.7)$ \\
\hline & Pediatric ward & $125(30.3)$ \\
\hline & Gynecology ward & $58(14)$ \\
\hline & $\begin{array}{l}\text { General ward (ICU and } \\
\text { ophthalmology unit) }\end{array}$ & $37(9)$ \\
\hline \multirow{3}{*}{$\begin{array}{l}\text { Severity of underlying } \\
\text { medical condition } \\
\text { (McCabe scores) }\end{array}$} & Non-fatal disease & $352(85.2)$ \\
\hline & Ultimately fatal disease & $40(9.7)$ \\
\hline & Rapidly fatal disease & $21(5.1)$ \\
\hline \multirow[b]{2}{*}{ Previous hospital admission } & Yes & $298(72.2)$ \\
\hline & No & $115(27.8)$ \\
\hline \multirow{2}{*}{$\begin{array}{l}\text { Surgical procedure on } \\
\text { current admission }\end{array}$} & Yes & $213(51.6)$ \\
\hline & No & $200(48.4)$ \\
\hline \multirow{2}{*}{$\begin{array}{lll}\begin{array}{l}\text { Wound } \\
\text { procedure }\end{array} & \text { other } & \text { than } \\
\end{array}$} & Yes & $15(3.6)$ \\
\hline & No & $398(96.4)$ \\
\hline \multirow[t]{2}{*}{ Naso gastric tube inserted } & Yes & $31(7.5)$ \\
\hline & No & $382(92.5)$ \\
\hline \multirow[t]{2}{*}{ Peripheral catheter inserted } & Yes & $361(87.4)$ \\
\hline & No & $52(12.6)$ \\
\hline \multirow[t]{2}{*}{ Urethral catheter inserted } & Yes & $63(15.3)$ \\
\hline & No & $350(84.7)$ \\
\hline \multirow[t]{2}{*}{ Fracture fixative inserted } & Yes & $38(9.2)$ \\
\hline & No & $375(90.8)$ \\
\hline \multirow[t]{2}{*}{ Antibiotic therapy } & Yes & $331(80.1)$ \\
\hline & No & $82(19.9)$ \\
\hline \multirow{2}{*}{ Length of stay (treatment) } & above median (5 days) & $189(45.8)$ \\
\hline & below or equals to median ( 5 days) & $224(54.2)$ \\
\hline
\end{tabular}


Table 2 General facility management of patient safety at inpatient wards

\begin{tabular}{|l|l|l|}
\hline Element & Characteristics & Frequency (\%) \\
\hline $\begin{array}{l}\text { Availability of hand washing } \\
\text { facilities (running tap water) }\end{array}$ & Yes & $276(66.8)$ \\
\hline $\begin{array}{l}\text { Availability of waste bin labeled by } \\
\text { black color for segregation of non- }\end{array}$ & Yes & $139(33.2)$ \\
\hline $\begin{array}{l}\text { contaminated waste in room } \\
\text { Availability of waste bin labeled by } \\
\text { yellow color for segregation of } \\
\text { contaminated waste in room }\end{array}$ & Yes & $412(99.7)$ \\
\hline $\begin{array}{l}\text { Is there sufficient ventilation } \\
\text { system }\end{array}$ & Yes & $1(0.3)$ \\
\hline & No & $325(8.7)$ \\
\hline
\end{tabular}

\section{Factors associated with HAIs}

There was a significant difference in mean length of hospital stay between participants with HAI and those without HAI (mean difference=3.383; 95\%CI: 2.291-4.474, $\mathrm{P}=0.000$ at $\mathrm{t}=6.090$, assuming t-test for equality of means).

Absence of waste bin (labeled by yellow color) for segregation of contaminated waste in room, severity of underlying medical condition such as admit with rapidly fatal disease, admit with ultimately fatal disease, length of hospital stay such as more than five days of hospital stay and absence of hand washing facilities were the four predictor variables associated with HAI in the b In multivariable logistic regression severity of underlying medical condition such as admit with rapidly fatal disease $(\mathrm{P}=0.001)$, admit with ultimately fatal disease $(\mathrm{P}=0.022)$; length of hospital stay such as more than five days of hospital stay, $(\mathrm{P}=0.028)$ and absence of hand washing facilities $(\mathrm{P}<0.001)$ were the three independent predictors of HAI. Thus, in this study, patients who admitted with rapidly fatal disease were significantly at high risk for developing HAI as compared to those admitted with non-fatal disease ( $\mathrm{P}=0.022)$. Similarly, the odds patients admitted with ultimately fatal disease were significantly more at risk to develop HAI than the counterparts $(\mathrm{P}=0.001)$.

The finding from this study also revealed, patients admitted at inpatient room, which have no hand washing facilities were strongly associated to increase the odds of acquire infection at health care setting $(\mathrm{P}<0.001)$. The odds of developing hospital acquired infection among patients stayed for more than five day (median hospital stay) were 2.056 times higher than those stayed for less than five days $(\mathrm{AOR}=2.056,95 \% \mathrm{CI}$ : 1.082-3.908), $(\mathrm{P}<0.05)$. 
Table 3 Predictive factors in Bi variable and Multivariable logistic regression analysis for the occurrence of HAI among study participants at inpatient wards in HUCSH

\begin{tabular}{|c|c|c|c|c|c|}
\hline \multirow[t]{2}{*}{ variable $^{\mathbf{a}}$} & \multirow[t]{2}{*}{ Category } & \multicolumn{2}{|l|}{ HAI } & \multirow[t]{2}{*}{ COR(95\%C.I) } & \multirow[t]{2}{*}{ AOR (95\%CI) } \\
\hline & & $\begin{array}{l}\text { Yes } \\
\mathrm{n}(\%)\end{array}$ & $\begin{array}{l}\text { No } \\
\mathrm{n}(\%)\end{array}$ & & \\
\hline \multirow[t]{2}{*}{ Sex } & Male & $\begin{array}{l}27 \\
(55.1)\end{array}$ & $\begin{array}{l}158 \\
(43.4)\end{array}$ & 1 & 1 \\
\hline & Female & $\begin{array}{l}22 \\
(44.9)\end{array}$ & $\begin{array}{l}206 \\
(56.6)\end{array}$ & $\begin{array}{l}0.625(0.343- \\
1.139)\end{array}$ & $\begin{array}{l}0.697 \quad(0.363- \\
1.337)\end{array}$ \\
\hline \multirow{2}{*}{$\begin{array}{l}\text { Peripheral } \\
\text { catheter } \\
\text { inserted }\end{array}$} & Yes & $\begin{array}{l}46 \\
(93.9)\end{array}$ & $\begin{array}{l}315 \\
(86.5)\end{array}$ & $\begin{array}{l}2.385 \quad(0.714- \\
7.967)\end{array}$ & $\begin{array}{l}1.9 \\
6.592)\end{array}$ \\
\hline & No & $\begin{array}{l}3 \\
(6.1)\end{array}$ & $\begin{array}{l}49 \\
(13.5)\end{array}$ & 1 & 1 \\
\hline \multirow{2}{*}{$\begin{array}{l}\text { Urinary } \\
\text { catheter } \\
\text { inserted }\end{array}$} & Yes & $\begin{array}{l}11 \\
(22.4)\end{array}$ & $\begin{array}{l}52 \\
(14.3) \\
\end{array}$ & $\begin{array}{l}1.737 \text { (0.835- } \\
3.613)\end{array}$ & $\begin{array}{l}1.327 \text { (0.591- } \\
2.981)\end{array}$ \\
\hline & No & $\begin{array}{l}38 \\
(77.6)\end{array}$ & $\begin{array}{l}312 \\
(85.7)\end{array}$ & 1 & 1 \\
\hline \multirow{2}{*}{$\begin{array}{l}\text { Fracture } \\
\text { fixative } \\
\text { inserted }\end{array}$} & Yes & $\begin{array}{l}8 \\
(16)\end{array}$ & $30(8.2)$ & $\begin{array}{l}2.172 \\
5.055)\end{array}$ & $\begin{array}{l}1.437 \quad(0.563- \\
3.664)\end{array}$ \\
\hline & No & $\begin{array}{l}41 \\
(83.7)\end{array}$ & $\begin{array}{l}334 \\
(91.8)\end{array}$ & 1 & 1 \\
\hline \multirow{3}{*}{$\begin{array}{l}\text { Severity of } \\
\text { underlying } \\
\text { medical } \\
\text { condition } \\
\text { (McCabe } \\
\text { scores) }\end{array}$} & $\begin{array}{l}\text { Non-fatal } \\
\text { disease }\end{array}$ & $\begin{array}{l}33 \\
(67.3)\end{array}$ & $\begin{array}{l}319 \\
(87.6)\end{array}$ & 1 & 1 \\
\hline & $\begin{array}{l}\text { Ultimately } \\
\text { fatal } \\
\text { Disease }\end{array}$ & $\begin{array}{l}11 \\
(22.4)\end{array}$ & $\begin{array}{l}29 \\
(8)\end{array}$ & $\begin{array}{l}3.667 \text { (1.679- } \\
8.008) *\end{array}$ & $\begin{array}{l}3.791 \quad(1.672- \\
8.597) *\end{array}$ \\
\hline & $\begin{array}{l}\text { Rapidly fatal } \\
\text { disease }\end{array}$ & $\begin{array}{l}5 \\
(10.2)\end{array}$ & $16(4.4)$ & $\begin{array}{l}3.021 \quad(1.040- \\
8.774) *\end{array}$ & $\begin{array}{l}3.689(1.208- \\
11.268)^{*}\end{array}$ \\
\hline \multirow[t]{2}{*}{$\begin{array}{l}\text { Length of } \\
\text { hospital stay } \\
\text { (treatment) }\end{array}$} & $\begin{array}{ll}\text { Below } & \text { or } \\
\text { equals } & \text { to } \\
\text { median } & \\
\text { ( } \leq 5 \text { days) } & \end{array}$ & $\begin{array}{l}18 \\
(36.7)\end{array}$ & $\begin{array}{l}206 \\
(56.6)\end{array}$ & 1 & 1 \\
\hline & $\begin{array}{l}\text { Above } \\
\text { median } \\
(>5 \text { days })\end{array}$ & $\begin{array}{l}31 \\
(63.3)\end{array}$ & $\begin{array}{l}158 \\
(43.4)\end{array}$ & $\begin{array}{l}2.245(1.212- \\
4.160)^{*}\end{array}$ & $\begin{array}{l}2.056(1.082- \\
3.908) *\end{array}$ \\
\hline \multirow{2}{*}{$\begin{array}{l}\text { Availability of } \\
\text { hand washing } \\
\text { facilities } \\
\text { (running tap } \\
\text { water) }\end{array}$} & Yes & $20(40.8)$ & $\begin{array}{l}256 \\
(69.8)\end{array}$ & 1 & 1 \\
\hline & No & $29(59.2)$ & $\begin{array}{l}110 \\
(30.2)\end{array}$ & $\begin{array}{l}3.347 \quad(1.863- \\
6.341)^{* *}\end{array}$ & $\begin{array}{l}3.49 \quad(1.849- \\
6.616)^{* *}\end{array}$ \\
\hline \multirow{2}{*}{$\begin{array}{l}\text { Availability of } \\
\text { waste bin } \\
\text { labeled } \\
\text { yellow by } \\
\text { color }\end{array}$} & Yes & $\begin{array}{l}33 \\
(67.3)\end{array}$ & $\begin{array}{l}292 \\
(80.2)\end{array}$ & 1 & 1 \\
\hline & No & $\begin{array}{l}16 \\
(32.7)\end{array}$ & $\begin{array}{l}72 \\
(19.8)\end{array}$ & $\begin{array}{l}1.966(1.026- \\
3.768)^{*}\end{array}$ & $\begin{array}{l}1.629(0.812- \\
3.268)\end{array}$ \\
\hline
\end{tabular}




\begin{tabular}{|c|c|c|c|c|c|}
\hline $\begin{array}{l}\text { for segregation } \\
\text { of } \\
\text { contaminated } \\
\text { waste in room }\end{array}$ & & & & & \\
\hline $\begin{array}{l}\text { Is there } \\
\text { sufficient }\end{array}$ & Yes & $\begin{array}{l}42 \\
(85.7)\end{array}$ & $\begin{array}{l}335 \\
(92)\end{array}$ & 1 & 1 \\
\hline $\begin{array}{l}\text { ventilation } \\
\text { system }\end{array}$ & No & $\begin{array}{l}7 \\
(14.3)\end{array}$ & $\begin{array}{l}29 \\
(8)\end{array}$ & $\begin{array}{ll}1.925 & (0.794 \\
4.667) & \end{array}$ & $\begin{array}{l}0.712 \quad(0.234- \\
2.171)\end{array}$ \\
\hline \multicolumn{6}{|c|}{$\begin{array}{l}\text { Note } \\
{ }^{a}=\text { Candidate variables for multivariable analysis at } \mathrm{p} \text {-value } \leq 0.20 ; \\
*=\text { Statistically significant association, } \mathrm{P}<0.05 ; \\
* *=\text { very strong statistically significant association, } \mathrm{P}<0.001 ; \\
1=\text { indicated the reference category }\end{array}$} \\
\hline
\end{tabular}




\section{Discussion}

This study was aimed to determine the prevalence of HAI and its associated factors among patients admitted for at least three days in HUCSH inpatient ward. Hence, the overall prevalence of HAI was $11.9 \%$.

The overall prevalence (11.9\%) obtained from this cross sectional study was comparable to a similar study conducted in Amhara regional state, Ethiopia (14.9\%) [9] and Ghana (14.4\%) [7].

In contrast, the overall prevalence $(11.9 \%)$ obtained from the current study was higher than the prevalence reported from a cross sectional study in eastern Ethiopia (7.4\%) [26][24][24][24][24][24][24][8]. The reason for this high (11.9\%) prevalence might be due to the comprehensive nature of current study, which involved all admitted patients including those in intensive care, with debilitating medical conditions, and had history of hospitalization, these might have contributed for the observed higher prevalence (11.9\%); whereas these was not in the contrast study [8]. This is in line with a retrospective case-control study in UK, given that additional intra hospital transfer increased the odds of acquiring HAI by 9\% [27].

Similarly, the overall prevalence identified in the current study (11.9\%) was high compared to prevalence reported from a point prevalence study in the USA (3.2\%) [4], and china 4.26\% [12]. However, it is low when compared to research conducted in Uganda (28\%) [28]. The discrepancy of the result could be due to differences in socio economic status of countries, the underlying medical conditions, and insufficient hand washing facilities. This is supported by a meta-analysis study, conducted on infection prevention practice of HCWs [15] and a cross sectional study on compliance with standard safety precaution done at the study setting [29]. In line with this evidence, a meta-analysis study in sub Saharan Africa, revealed the impact of HAI in resourcepoor countries, was attributed with overstretched health workforce and a high burden of community-acquired infection, variability of compliance with hand hygiene and scarcity of resource within the region [13].

In the current study, the prevalence of HAIs at major inpatient wards indicated a large variability that ranges from $2 \%$ in general wards to $36.7 \%$ in pediatric wards. The reason for high proportion of infection at pediatric ward could be due to their admission diagnosis that admitted with fatal disease was associated with HAI. Thus pediatric patients are more prone for infection due to the immune susceptibility of pediatric population. This was supported by a cross sectional study in 
Addis Ababa, revealed that patients age less than 14 years were $72.7 \%$ more likely to develop HAI compared to older age patients [10] and also in south east Ethiopia, that children with underlying disease conditions were in higher risk to develop HAIs [15].

In line with this, there was a significance difference in length of hospital stay between patients developing HAI and without infection ( $\mathrm{P}=0.000$ at $\mathrm{t}=6.090)$. Thus, the high proportion of infection observed at orthopedic wards could be due to the type of surgery. This was also supported by studies in the UK, given that having orthopedic surgery were at high risk of infection were associated with longer duration of hospital stay [3] and also in Uganda, given that the higher proportion of infection (47\%) were reported from surgery ward [28].

The finding from multivariate analysis showed, more than five days of inpatient stay (treatment), severity of underlying medical condition (McCabe score), and absence of hand washing facilities (running tap water) were the three independent variables predicting for HAI. Thus, length of treatment in a given ward was significantly associated with the occurrence of hospital acquired infections ( $\mathrm{P}=0.028)$, where the odds of developing hospital acquired infection among patients who stayed for more than five day (median hospital stay) were 2.056 times higher than those who stayed for less than five days. This is in line with the findings of a cross sectional study in eastern Ethiopia [8], south eastern Ethiopia [17] and china [19].

Similarly, the odds of patients admitted with ultimately fatal disease were significantly at high risk of developing HAI ( $\mathrm{P}=0.001)$. Consequently, patients who are admitted with rapidly fatal disease were significantly associated to develop HAI as compared to those admitted with non-fatal disease $(\mathrm{P}=0.022)$. The possible reason for observed association in the current study might be due to multiple comorbidity and immunosuppression effects of these diseases. This is in line with the findings from studies in Adama, where renal disease and type 2 diabetic mellitus (DM), were significantly associated with HAI [18] was also supported from a study in China, where patients admitted with rapidly fatal disease were significantly associated with the occurrence of HAI[19]. In the current study availability of hand washing facilities (running tap water) was also inversely associated with HAI. Hence, patients admitted in an inpatient room, without hand washing facilities were strongly associated with the acquiring of infection $(\mathrm{P}<0.001)$. This result was supported by a case control study in Ethiopia, which revealed that presence of hand washing facilities in rooms were 19\% less likely to acquire infection at hospital [24]. 


\section{Conclusion}

The most frequently reported specific sites of HAIs were SSI, and BSI/septicemia. The prevalence of HAI showed variation between wards. Hence, the higher proportion were revealed from orthopedic and pediatric wards.

In addition, severity of admission medical condition (based on McCabe score), such as admitted with ultimately fatal, and rapidly fatal disease; more than five days of hospital stay (treatment) and absence of hand washing facilities (running tap water) were the three independent predictors of HAI.

\section{Acknowledgments}

The authors would like to thank Hawassa University for ethically approve this research topic and sponsorship of this study. They also acknowledge the management of Hawassa university comprehensive specialized hospital, healthcare workers, and patients for their contribution to make this study possible. The appreciation from authors also goes to all data collectors and our friends, for their cheerful support and encouragement while we are doing this thesis.

\section{Author contributions}

All authors contributed toward data analysis, drafting and critically revising the paper, and agree to be accountable for all aspects of the work.

\section{Disclosure}

I, the undersigned, declare that this Mph research is my original work, has not been presented for a degree in another university and that all source of materials used for the thesis has been duly acknowledged. Furthermore, the authors report no conflicts of interest in this work.

Correspondence: Getachew Melake

\section{Abbreviations}

AOR _ adjusted odd ratio;

BSI_ Blood Stream Infection

CDC/ NHSN _ Centre for Disease Control/National HealthCare Safety Network

CI_Confidence interval;

COR_Crude odds ratio; 
HAI_Hospital Acquired Infection

HMIS_Health Management Information System

HUCSH_Hawassa University comprehensive Specialized Hospital

ICU_ Intensive care Unit

IPP_Infection prevention and control Practice

LOS_Length of Stay

n_number of participants

SPSS_Statistical plan for social science

SSI_Surgical Site Infection

UTI_Urinary Tract Infections

\section{References}

1. Khan HA, B.F., Mehboob R, Nosocomial infections: Epidemiology, prevention, control and surveillance. Asian Pacific Journal of Tropical Biomedicine, 2017. 7(5): p. 478-82.

2. Care, L.-t., National Healthcare Safety Network (NHSN) Overview. 2021.

3. Haque, M., et al., Health care-associated infections - an overview. Infect Drug Resist, 2018. 11: p. 2321-2333.

4. Magill, S.S., et al., Antimicrobial Use in US Hospitals: Comparison of Results From Emerging Infections Program Prevalence Surveys, 2015 and 2011. Clinical Infectious Diseases, 2021. 72(10): p. 1784-1792.

5. Rothe, C., C. Schlaich, and S. Thompson, Healthcare-associated infections in sub-Saharan Africa. Journal of Hospital Infection, 2013. 85(4): p. 257-267.

6. Nekkab, N., et al., Spread of hospital-acquired infections: A comparison of healthcare networks. PLoS Comput Biol, 2017. 13(8): p. e1005666. 
7. Labi, A.K., et al., Multi-centre point-prevalence survey of hospital-acquired infections in Ghana. Journal of Hospital Infection, 2019. 101(1): p. 60-68.

8. Tolera, M., et al., Are Invasive Procedures and a Longer Hospital Stay Increasing the Risk of Healthcare-Associated Infections among the Admitted Patients at Hiwot Fana Specialized University Hospital, Eastern Ethiopia? Adv Prev Med, 2020. 2020: p. 6875463.

9. Yallew, W.W., A. Kumie, and F.M. Yehuala, Point prevalence of hospital-acquired infections in two teaching hospitals of Amhara region in Ethiopia. (1179-1365 (Print)).

10. Tassew, S.G., et al., Management of hospital-acquired infections among patients hospitalized at Zewditu memorial hospital, Addis Ababa, Ethiopia: A prospective crosssectional study. PLoS One, 2020. 15(4): p. e0231949.

11. Loftus, M.J., et al., Prevalence of healthcare-associated infections and antimicrobial use among inpatients in a tertiary hospital in Fiji: a point prevalence survey. Antimicrobial Resistance \& Infection Control, 2020. 9(1): p. 146.

12. $\mathrm{Wu}, \mathrm{Y} . \mathrm{-L}$. , et al., An 8-year point-prevalence surveillance of healthcare-associated infections and antimicrobial use in a tertiary care teaching hospital in China. Epidemiology \& Infection, 2019. 147.

13. Irek, E.O., et al., A systematic review of healthcare-associated infections in Africa: An antimicrobial resistance perspective. African journal of laboratory medicine, 2018. 7(2): p. 796-796.

14. Shukla, B.S., et al., Bloodstream Infection Risk, Incidence, and Deaths for Hospitalized Patients during Coronavirus Disease Pandemic. Emerging infectious diseases, 2021. 27(10): p. 2588. 
15. Sahiledengle, B., Y. Tekalegn, and D. Woldeyohannes, The critical role of infection prevention overlooked in Ethiopia, only one-half of health-care workers had safe practice: A systematic review and meta-analysis. PLoS One, 2021. 16(1): p. e0245469.

16. Ali, S., et al., Healthcare associated infection and its risk factors among patients admitted to a tertiary hospital in Ethiopia: longitudinal study. Antimicrob Resist Infect Control, 2018. 7: p. 2.

17. Sahiledengle, B., et al., Incidence and risk factors for hospital-acquired infection among paediatric patients in a teaching hospital: a prospective study in southeast Ethiopia. BMJ Open, 2020. 10(12): p. e037997.

18. Chernet, A.Z., et al., Burden of Healthcare-Associated Infections and Associated Risk Factors at Adama Hospital Medical College, Adama, Oromia, Ethiopia. Drug, Healthcare and Patient Safety, 2020. 12: p. 177.

19. Wang, L., et al., Epidemiology and risk factors for nosocomial infection in the respiratory intensive care unit of a teaching hospital in China: A prospective surveillance during 2013 and 2015. (1471-2334 (Electronic)).

20. Mathur, P., Prevention of Healthcare-Associated Infections in Low- and Middle-Income Countries: The 'Bundle Approach'. Indian Journal of Medical Microbiology, 2018. 36(2): p. $155-162$.

21. Wodajo, S., M. Belayneh, and S. Gebremedhin, Magnitude and Factors Associated With Post-Cesarean Surgical Site Infection at Hawassa University Teaching and Referral Hospital, Southern Ethiopia: A Cross-sectional Study. Ethiop J Health Sci, 2017. 27(3): p. 283-290. 
22. Alemayehu T, T.E., Ayalew S, Nigusse B, Yeshitila B, Amsalu A, High burden of Nosocomial infections caused by multi-drug Re-sistant pathogens in pediatric patients at Hawassa university comprehensive specialized hospital. Ethiopian Medical Journal, 2019.

58.

23. Norrick, B., et al., Health Care-associated infections studies project: An American Journal of Infection Control and National Healthcare Safety Network data quality collaboration case study. Am J Infect Control, 2021. 49(2): p. 224-225.

24. Yallew, W.W., A. Kumie, and F.M. Yehuala, Risk factors for hospital-acquired infections in teaching hospitals of Amhara regional state, Ethiopia: A matched-case control study. PLoS One, 2017. 12(7): p. e0181145.

25. Chartier, Y. and C. Pessoa-Silva, Natural ventilation for infection control in health-care settings. 2009.

26. !!! INVALID CITATION !!! .

27. Boncea, E.E., et al., Association between intrahospital transfer and hospital-acquired infection in the elderly: a retrospective case-control study in a UK hospital network. BMJ Qual Saf, 2021. 30(6): p. 457-466.

28. Greco, D. and I. Magombe, Hospital acquired infections in a large north Ugandan hospital. J Prev Med Hyg, 2011. 52(2): p. 55-8.

29. Bekele, T., et al., Compliance with standard safety precautions and associated factors among health care workers in Hawassa University comprehensive, specialized hospital, Southern Ethiopia. PLoS One, 2020. 15(10): p. e0239744. 
Figures

\section{Image not available with this version}

Figure 1

Proportional allocation of sample size to type of inpatient wards in HUCSH, based on size of inpatient beds. 